\title{
Assessment of fire severity and species diversity in the southern Appalachians using Landsat TM and ETM+ imagery
}

\author{
Michael C. Wimberly*, Matthew J. Reilly \\ Warnell School of Forest Resources, University of Georgia, Athens, Georgia 30602, United States
}

Received 21 October 2005; received in revised form 14 March 2006; accepted 22 March 2006

\begin{abstract}
Relatively little is known about the disturbance ecology of large wildfires in the southern Appalachians. The occurrence of a 4000-ha wildfire in the Linville Gorge Wilderness area in western North Carolina has provided a rare opportunity to study a large fire with a range of severities. The objectives of this study were to 1) assess the potential for using multi-temporal Landsat imagery to map fire severity in the southern Appalachians, 2) examine the influences of topography and forest community type on the spatial pattern of fire severity; and 3) examine the relationship between predicted fire severity and changes in species richness. A non-linear regression equation predicted a field-based composite burn index (CBI) as a function of change in the Normalized Burn Ratio (dNBR) with an $R^{2}$ of 0.71 . Fire severity was highest on drier landforms located on upper hillslopes, ridges, and on southwest aspects, and was higher in pine communities than in other forest types. Predicted CBI was positively correlated with changes in species richness and with the post-fire cover of pine seedlings (Pinus virginiana, P. rigida, and P. pungens), suggesting that burn severity maps can be used to predict community-level fire effects across large landscapes. Despite the relatively large size of this fire for the southern Appalachians, severity was strongly linked to topographic variability and pre-fire vegetation, and spatial variation in fire severity was correlated with changes in species richness. Thus, the Linville Gorge fire appears to have generally reinforced the ecological constraints imposed by underlying environmental gradients.
\end{abstract}

(C) 2006 Elsevier Inc. All rights reserved.

Keywords: Fire severity; Fire ecology; Normalized burn ratio; Topography; Fuels; Landsat TM; Landsat ETM+; Southern Appalachians

\section{Introduction}

Fire was historically a major influence on landscape patterns and species diversity in the forests of the southern Appalachians (Delcourt \& Delcourt, 1997). It is generally thought that frequent, low-intensity fires set by Native Americans promoted regeneration of pine and oak species on dry upper slopes and ridges, but rarely spread into moist sheltered coves and valleys. Fire remained an important part of the disturbance regime after European settlement, with forests in some parts of the region burning approximately every thirteen years (Harmon, 1982). The advent of fire suppression in the 1930's reduced the frequency and sizes of fires (Barden \& Woods, 1973) causing

\footnotetext{
* Corresponding author. GISc Center of Excellence, Wecota Hall-506B Brookings, SD 57007-3510, United States. Tel.: +1 605688 5350; fax: +1 605 6885227.

E-mail address: michael.wimberly@sdstate.edu (M.C. Wimberly).
}

declines in pine and oak regeneration (Harrod et al., 1998; Williams \& Johnson, 1992). The recent occurrence of a 4000-ha wildfire in western North Carolina has provided a rare opportunity for research into the ecological effects of largescale disturbances in the southern Appalachians.

Current ecological theory posits that the behavior and effects of large, infrequent disturbances are qualitatively different from more frequent low- to moderate-severity events (Romme et al., 1998). Although the influences of fuels and topography on fire behavior and fire effects are widely recognized, these constraints may be relatively weak in the case of larger, highintensity conflagrations that are driven primarily by high winds and low fuel moisture (Turner \& Romme, 1994). A fire behavior modeling experiment found that once weather conditions reached a threshold, all age-classes of subalpine forests were equally susceptible to crown fires regardless of their fuel loading or canopy structure (Bessie \& Johnson, 1995). However the empirical evidence for this hypothesis is mixed. For the 
large, high-intensity wildfires occurring in Yellowstone National Park during the summer of 1988, the probability of highseverity crown fire was greater than expected in latesuccessional forests, but was unrelated to stand density or topography (Turner et al., 1999). In contrast, patterns of severity in a wildfire that burned 4500 ha of subalpine forest in northwestern Colorado were constrained by forest cover type, forest structure, topography, and disturbance history (Bigler et al., 2005). A study of a 3000-ha landscape in coastal Oregon found that topography had a weak influence on the pattern of old-growth remnants left by a large $(>100,000 \mathrm{ha})$ fire in the mid-19th century (Wimberly \& Spies, 2001), whereas another study in a nearby landscape impacted by the same fire found much stronger topographic controls on the distribution of old growth (Harcombe et al., 2004). In the boreal mixedwood forest of Alberta, major forest cover types differed considerably in their probability of burning at both local and regional scales, and no differences were found between small and large fires (Cumming, 2001). However, a study of wildfire patterns in Portugal found that land cover patterns had a stronger influence on small fires than large fires (Nunes et al., 2005).

More assessments of large, severe-weather fires in a variety of forest ecosystems are needed to test the generality of the Turner and Romme (1994) hypothesis. From the standpoint of fire management, it is important to recognize physical environments that are inherently susceptible to high-intensity fire. Furthermore, it is valuable to know whether fire effects could be modified by manipulating the spatial pattern of vegetation. From an ecological standpoint, it is important to determine whether large, high-severity wildfires have unique ecological effects that cannot be easily predicted from our knowledge of more frequent, low-severity events. Because of the massive amount of data that is needed to adequately characterize the spatial pattern of a large fire, satellite remote sensing has emerged as an important tool for monitoring fire effects (Key \& Benson, 2002). Patterns of burn severity can be measured as changes in spectral signatures that occur following a fire. Then, if physical or biological changes following the fire are related to burn severity, these severity maps can be used to make predictions of fire effects (Cocke et al., 2005).

Several studies have demonstrated the utility of Landsat Thematic Mapper (TM) and Enhanced Thematic Mapper (ETM+) imagery for mapping fire severity. A single image acquired soon after the fire is often sufficient for developing burn maps, and this approach has been used to map spatial variation in fire severity in subalpine forests following the 1988 Yellowstone fires (Turner et al., 1994), and in Pacific Northwest conifer forests following the 1991 Warner Creek burn (Kushla \& Ripple, 1998). However, multi-date imagery is advantageous because it accounts for prefire variability in vegetation structure. Change in the Normalized Burn Ratio (NBR), a ratio of Landsat bands 4 (near infrared) and 7 (middle infrared), appears to be a particularly effective index of burn severity. Studies have found correspondence between change in NBR and field-based severity metrics in a variety of forest types in the southwestern United States (Cocke et al., 2005; Miller \& Yool, 2002), mixed-conifer forests in the Sierra Nevada (Van Wagtendonk et al., 2004), and boreal forests of interior Alaska
(Epting et al., 2005). Comparisons of multiple techniques have found that burn severity mapping based on the NBR performs well compared to other types of remote sensing indices such as the normalized difference vegetation index (NDVI), principal components transformations, and tasseled cap transformations (Epting et al., 2005; Miller \& Yool, 2002; Rogan \& Yool, 2001).

To date, the NBR and related remote sensing methods have primarily been applied to study fires in coniferous forests of the western United States. It is uncertain whether they will be as effective for mapping fire severity in hardwood-dominated landscapes of the southern Appalachians. Furthermore, because large, high-intensity fires occur so rarely in this region, it is not known whether vegetation and topography exert a strong influence over patterns of burn severity, or whether burn severity maps can be used to make spatial predictions of fire effects. The objectives of this research were therefore to 1) gauge the potential for using multi-temporal satellite imagery to map fire severity in forests of the southern Appalachians; 2) assess the influences of topography and pre-fire forest community type on the spatial pattern of fire severity; and 3) determine whether remote-sensing derived measurements of fire severity are related to post-fire changes in species richness.

\section{Methods}

\subsection{Study area}

Linville Gorge is a federally designated wilderness area located in the Blue Ridge Escarpment near Boone, North Carolina, USA. Elevations range from approximately $320 \mathrm{~m}$ at the bottom of the gorge to $1250 \mathrm{~m}$ on upper ridges. Topography is extremely rugged; both sides of the gorge contain prominent cliff-like bluffs that divide upper and lower slopes (Fig. 1). The majority of Linville Gorge is unlogged and it is one of the largest remaining tracts of old-growth forest in the region. Large, high-intensity fires occurred in 1860 and 1915, and the last widespread surface fires occurred in the 1950's. In November 2000 a wildfire from an unattended campfire burned approximately 4000 ha in and around the wilderness area.

The presence of strong environmental gradients is reflected in a diverse assemblage of forest community types within the gorge (Newell \& Peet, 1998). Upper slopes are dominated by pine and oak forests which are composed of several species of eastern yellow pine (Pinus virginiana, Pinus rigida, and Pinus pungens) and oak (Querucs coccinea, Quercus montana, Quercus alba) in the overstory with a thick layer of ericaceous shrubs (Kalmia latifolia, Vaccinium spp.) in the understory. Rocky outcrops found within the bluffs are dominated by ericaceous shrubs such as piedmont rhododendron (Rhododendron minus). Slopes below the bluffs are dominated by chestnut oak $(Q$. prinus $)$ and are classified as acidic slopes and montane oak forests. Acidic slopes are distinguished by abundant rhododendron (Rhododendron maximum) in the understory with white pine (Pinus strobus) and red maple (Acer rubrum) present in varying amounts. Montane oak forests are dominated by chestnut oak $(Q$. montana) and include tulip poplar (Liriodendron tulipifera) and dogwood (Cornus florida). Moister areas including sheltered ravines 
(a)

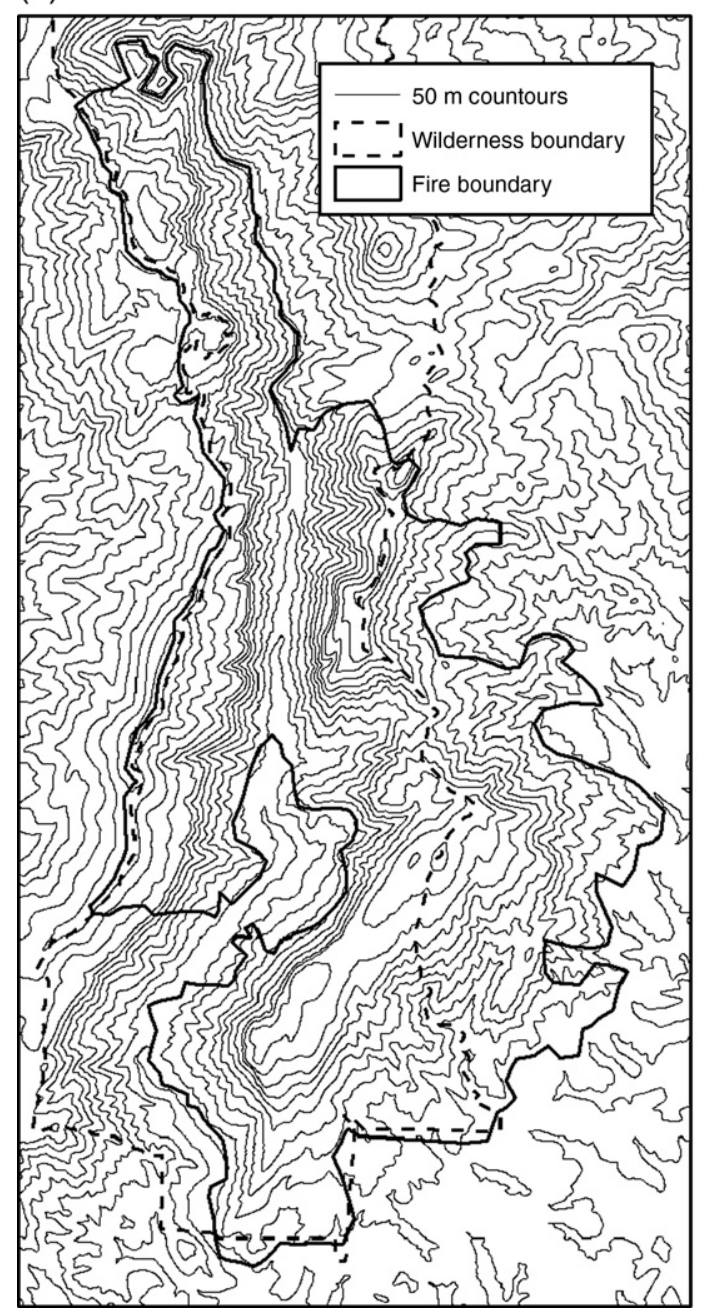

(b)

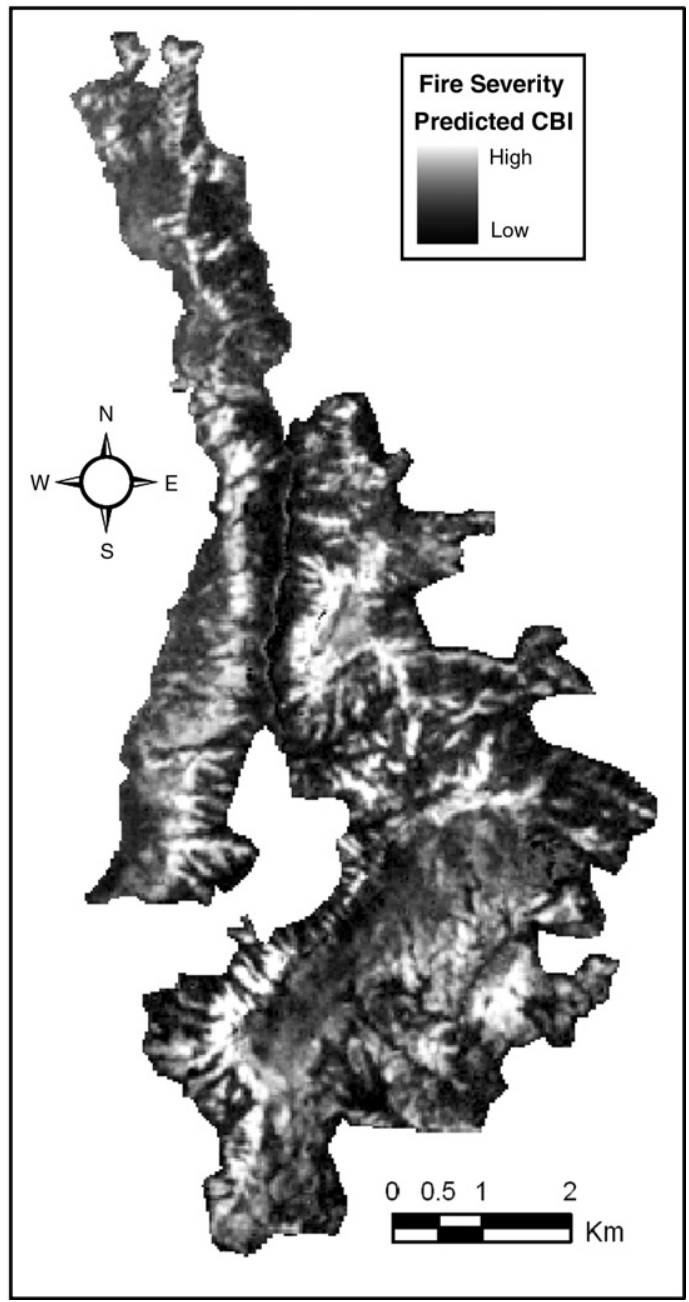

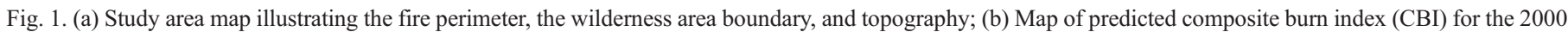
Linville Gorge fire.

descending from upper slopes and the bottom of the gorge along the Linville River are classified as acidic coves and are dominated by eastern hemlock (Tsuga canadensis) in the canopy and thick $R$. maximum in the understory.

\subsection{Satellite imagery}

Two satellite images were obtained to represent pre- and post-burn landscape conditions: a Landsat TM image from June of 2000, and a Landsat ETM+ image from June of 2001. These datasets were obtained from the Multi-Resolution Land Characteristics Consortium (MRLC) archive as georeferenced and terrain-corrected images. Digital numbers were converted to reflectance values using the COST method of Chavez (1996). Adjustments were made for inter-date differences in atmospheric conditions using the dark object subtraction technique of Moran et al. (1992). The Normalized Burn Ratio (NBR) was then computed for each image as

$\mathrm{NBR}=1000 \times \frac{\left(R_{4}-R_{7}\right)}{\left(R_{4}+R_{7}\right)}$ where the $R_{4}$ and $R_{7}$ values were reflectance for bands 4 and 7 . Change in NBR following the fire was computed as

$\mathrm{dNBR}=\mathrm{NBR}_{\text {pre }}-\mathrm{NBR}_{\text {post }}$

where $\mathrm{NBR}_{\text {pre }}$ was from the 2000 pre-fire image and $\mathrm{NBR}_{\text {post }}$ was from the 2001 post-fire image.

A map of the fire perimeter was generated by manually digitizing the dNBR layers, using a $15-\mathrm{m}$ false-color infrared ASTER image from June of 2001 as an additional reference image. Much of the fire's outer perimeter was located along natural firebreaks such as rivers, or along roads and trails that were used as firebreaks during fire suppression efforts. A geographic information system (GIS) database that contained layers of rivers, roads, and trails was used to identify these firebreaks when digitizing the fire boundary.

\subsection{Field data and calibration}

Field data from a total of 57 plots was obtained from three sources. The first data set consisted of 21 remeasurement plots. 
These were $400 \mathrm{~m}^{2}(20 \mathrm{~m} \times 20 \mathrm{~m})$ permanent vegetation plots that were initially established in 1992 (Newell \& Peet, 1998), and were relocated and resurveyed in 2003 to examine plant community dynamics after the fire (Reilly, 2004). The locations of these plots were measured using a handheld GPS. The second data set included 11 additional unburned plots from the original 1992 survey. The locations of these plots were measured from plot locations marked on 1:12,000 aerial photographs. The third data set consisted of $25700 \mathrm{~m}^{2}$ (15 m radius) plots that were surveyed in the fall of 2004 using the methodology of Key and Benson (2002) and mapped with a handheld GPS unit. The locations of these additional plots were chosen subjectively, with an objective of generating a combined distribution of dNBR values (from all three data sources) that reflected the overall distribution of dNBR values within the fire perimeter.

A Composite Burn Index (CBI) was computed for each of these field plots using a modified version of the FIREMON landscape assessment methodology (Key \& Benson, 2002). This index was based on field estimates of the percentage of stem mortality in the tall shrub/small tree stratum, and estimates of percent canopy mortality in the intermediate and large tree strata. These particular metrics were chosen because they were all measured consistently across the various sources of field data, and because they could be reliably measured 3-4 years after the fire. These metrics were recorded as index values ranging between 0 and 3 , with higher numbers indicating greater mortality (Key \& Benson, 2002), and the CBI was a computed as a weighted average with weights of 1,2 , and 3 assigned to the shrub/small tree, intermediate tree, and large tree strata. This weighting put more emphasis on the mortality of larger trees, which were the most reliable field-based indicators of long-term fire effects. The composite CBI values were rescaled to range between 0 and 1 , with unburned plots assigned a CBI value of zero. Each plot was associated with the dNBR measurement from the nearest pixel by overlaying plot centroids on the dNBR image. Non-linear regression was used to fit an equation relating the observed $\mathrm{CBI}$ indices to $\mathrm{dNBR}$, and this equation was then used to predict CBI for all pixels falling inside the fire perimeter.

\subsection{Spatial analysis}

Elevation, slope, and aspect measurements were obtained from a 30-m digital elevation model. A topographic wetness index (Beven \& Kirkby, 1979) was created using the TOPOCROP ArcView extension (Schmidt \& Persson, 2003). A smoothing parameter of 1 was used to identify all ridges, and a mean filter was applied to minimize small scale heterogeneity in index values. A map of pre-fire forest communities (Newell \& Peet, 1998) was obtained from the USFS and used to identify rocky outcrops, pine forests, oak forests, and hemlock forests, which represented the major cover types and fuel complexes in the gorge. Elevation, slope, and topographic wetness values were grouped into four classes based on quartiles, and aspect was grouped into eight 45-degree classes corresponding with the major compass directions: N, NE, E SE S, SW W and NW. The mean and standard deviation of predicted CBI were computed for each of these vegetation and topographic classes. Because a reliable forest community map was only available for the Linville Gorge Wilderness, burned areas outside the wilderness were not included in the vegetation overlay analysis.

Linear regression analysis was used to model predicted CBI was a function of topographic and vegetation effects. Topographic variables were continuous, whereas vegetation classes were converted to indicator variables for the dominant cover types. The variable for the oak community type was not included in the modeling, and thus served as the baseline against which the parameter values for the other community types were compared. Aspect was converted into a heat-load index ranging from 0 to 1 with highest values for southwest slopes and lowest values for northeast slopes (McCune \& Keon, 2002). An arcsine square root transform was applied to both the predicted $\mathrm{CBI}$ and the heat load index. Prior to the modeling, the original $30 \mathrm{~m}$ grids were aggregated to $90 \mathrm{~m}$ by computing the mean of each independent and dependent variable within a $3 \times 3$ pixel window. This aggregation was carried out to reduce the potential effects of georegistration errors among the multiple layers, and to reduce the computational burden of fitting an autoregressive model. The total area modeled encompassed the $316590 \mathrm{~m}$ pixels (2564 ha) within the Linville Gorge Wilderness for which both topographic and vegetation data were available.

We initially applied standard linear regression methods based on ordinary least squares. However, strong spatial autocorrelation of the residuals indicated that the assumption of independent errors was violated. Therefore, we also computed a simultaneous autoregressive model that explicitly incorporated spatial autocorrelation (Haining, 2003). We applied the spatial error form of the simultaneous autoregressive model

$\mathbf{Y}=\mathbf{X} \boldsymbol{\beta}+\lambda \mathbf{W}(\mathbf{Y}-\mathbf{X} \boldsymbol{\beta})+\boldsymbol{\varepsilon}$

where $\mathbf{Y}$ is a vector of dependent variables, $\mathbf{X}$ is a matrix of independent variables, $\boldsymbol{\beta}$ is a vector of parameters, $\lambda$ is the autoregressive parameter that captures the degree of spatial autocorrelation among neighboring observations, $\mathbf{W}$ is a spatial weights matrix that defines the neighbors of each pixel, and $\boldsymbol{\varepsilon}$; is a vector of uncorrelated errors. This formulation can be interpreted as a linear regression carried out on spatially filtered

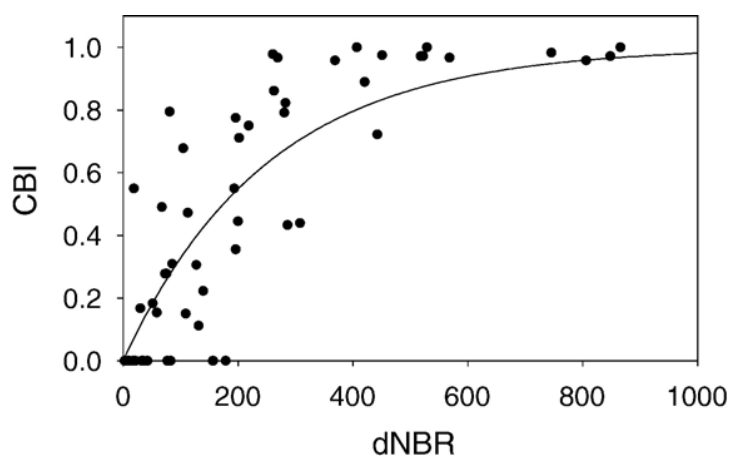

Fig. 2. Modified composite burn index (CBI) from 57 field plots versus change in the normalized burn ratio (dNBR) based on Landsat images from 2000 and 2001. The solid line represents the regression equation $\mathrm{CBI}=1-$ $\exp (-0.0039733 \mathrm{dNBR})$. 

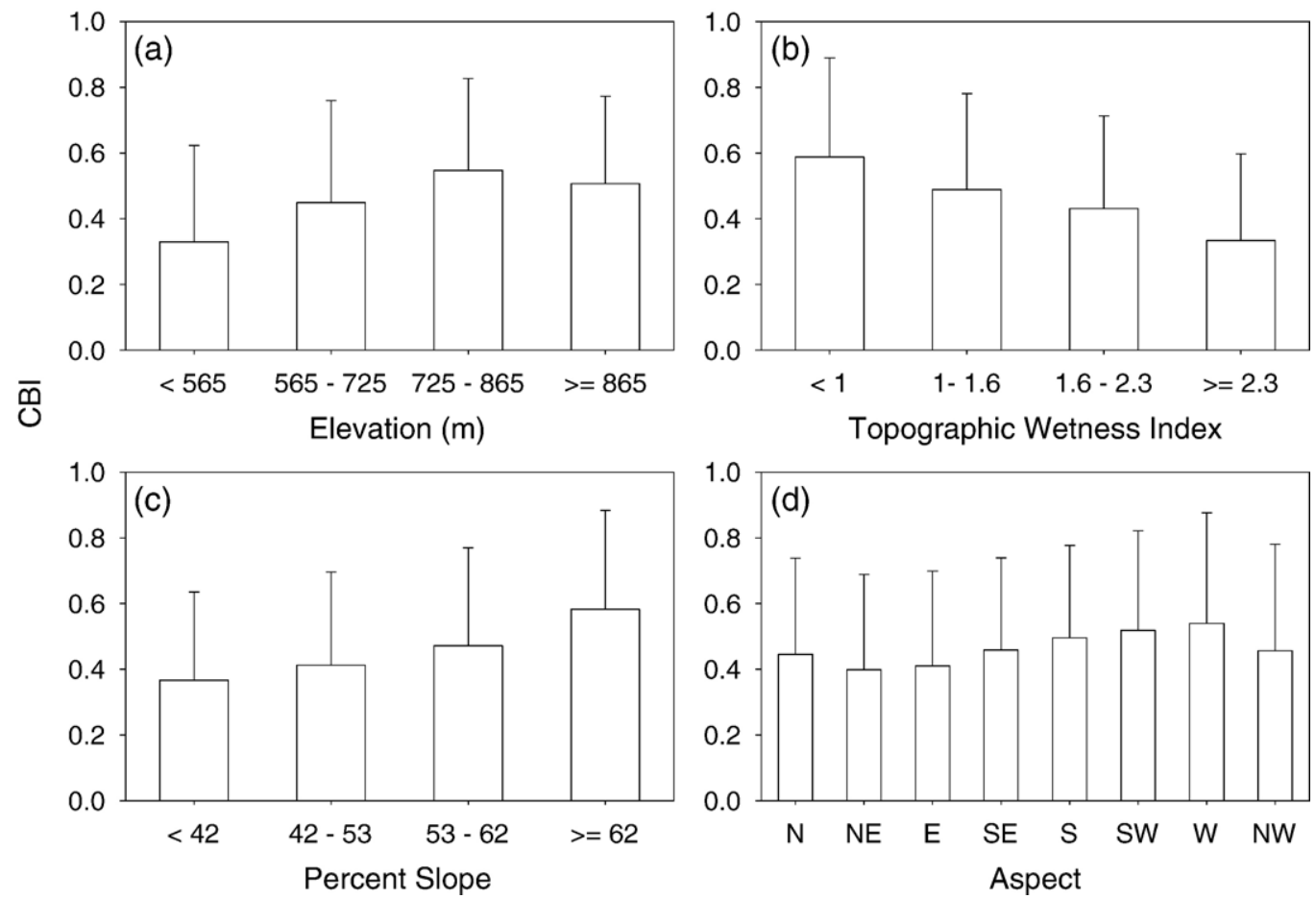

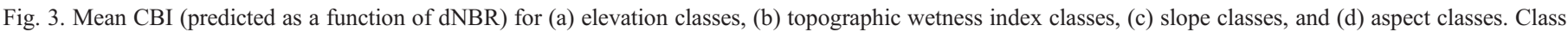
groupings for elevation, topographic wetness index, and slope are based on quartiles. Error bars represent the standard deviation of CBI for each class.

dependent and independent variables (Anselin, 2002). The spatial weights matrix was defined using a queen's rule, in which the neighborhood of each pixel consisted of the eight nearest horizontal and diagonal neighbors. Moran's I correlograms were computed over a range of lag distances to quantify spatial autocorrelation in the residuals from the ordinary least squares model and the spatially autoregressive model. Modeling was carried out in the $R$ language environment (R Development Core Team, 2005) using the spdep package for spatial autoregression (Bivand, 2002).

Detailed pre- and post-fire vegetation surveys were available for the 21 remeasurement plots. Pre-fire vegetation measurements were taken in 1992, and post-fire vegetation measurements were taken in 2003. Despite a major drought during the



Fig. 4. Mean CBI (predicted as a function of dNBR) for the four major community types in Linville Gorge. Error bars represent the standard deviation of CBI for each community type. late 1990's and a subsequent infestation of southern pine beetle (Dendroctinus frontalis), comparisons of pre- and post-fire plant community composition from unburned permanent plots showed that changes were minimal in the absence of fire (Reilly et al., 2006). Thus, changes in the burned plots resulted primarily from the fire, and not from successional changes that occurred prior to 2000. Species richness for each remeasurement plot was estimated as the mean species richness computed on 2-4 $100 \mathrm{~m}^{2}$ subplots. A complete description of the field sampling protocols is provided in Newell and Peet (1998) and Reilly (2004). Changes in species richness were calculated separately for trees, shrubs, and herbs. Pearson correlation coefficients $(r)$ between predicted CBI and changes in species

Table 1

Fitted coefficients and $p$-values from the standard least squares and spatial autoregressive models of $\mathrm{CBI}$ as a function of topographic and vegetation variables

\begin{tabular}{lllllr}
\hline Variables & \multicolumn{2}{l}{ Ordinary least squares $^{\mathrm{a}}$} & & \multicolumn{2}{c}{ Spatial autoregressive } \\
\cline { 2 - 3 } & Coefficient & $p$-value & & Coefficient & $p$-value \\
\hline Intercept & 0.62425 & $<0.001$ & & 0.64914 & $<0.001$ \\
Elevation & 0.10093 & $<0.001$ & & 0.16817 & $<0.001$ \\
Slope & 0.07375 & $<0.001$ & & 0.01794 & 0.005 \\
Topographic wetness & -0.05857 & $<0.001$ & & -0.06069 & $<0.001$ \\
$\quad$ index & & & & \\
Heat Load Index & 0.05336 & $<0.001$ & & 0.05231 & $<0.001$ \\
Pine community & 0.33140 & $<0.001$ & & 0.23391 & $<0.001$ \\
Hemlock community & 0.14156 & $<0.001$ & & 0.12089 & $<0.001$ \\
Lambda & NA & NA & 0.87701 & $<0.001$ \\
\hline
\end{tabular}

${ }^{\text {a }} R^{2}=0.41$, Akaike's Information Criterion $=69.2$.

b Pseudo- $R^{2}=0.77$, Akaike's Information Criterion $=-2341.9$. 


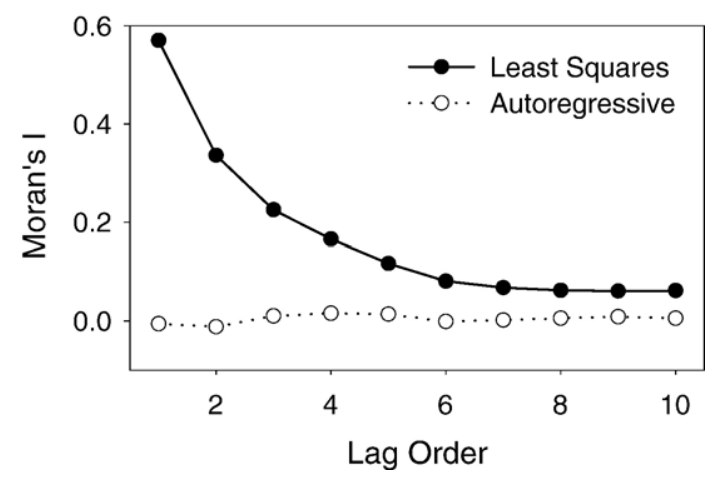

Fig. 5. Moran's I correlogram of residuals from the ordinary least squares and spatially autoregressive models of $\mathrm{CBI}$ as a function of topography and vegetation. Higher values of Moran's I indicate more spatial autocorrelation at a given lag distance. Neighboring pixels were defined based on the queen's rule (eight nearest neighbors). The first-order lag encompasses all of a pixel's neighbors; the secondorder lag encompasses all neighbors of a pixel's first-order neighbors; etc.

richness were examined to assess the potential for using burn severity maps to predict biodiversity responses to fire.

Combined cover of yellow pine seedlings (P. virginiana, P. rigida, $P$. and pungens) was estimated for each 2-4 $100 \mathrm{~m}^{2}$ subplots within each remeasurement plot using the following cover classes: $0-1 \%, 1-2 \%, 2-5 \%, 5-10 \%, 10-25 \%, 25-50 \%$, $50-75 \%, 75-95 \%, 95-100 \%$. The midpoints of these cover classes were averaged to generate a composite value for each remeasurement plot. Because of the skewed distribution of yellow pine seedlings, Spearman's rank correlation $(\rho)$ was used to assess the relationship between predicted CBI and pine seedling cover.

\section{Results}

The relationship between $\mathrm{dNBR}$ and CBI was non-linear, with CBI increasing rapidly as dNBR increased from 0 to 200 , and reaching an asymptote of 1.0 at a dNBR of approximately 500 (Fig. 2). Several non-linear equation forms were examined to find one that maximized the fit of the observed data, met statistical assumptions (normality and constant variance of residuals), and produced predictions bounded within the possible range of CBI $(0-1.0)$. Based on these criteria, the following equation was chosen to predict $\mathrm{CBI}$ as a function of $\mathrm{dNBR}$

$$
\mathrm{CBI}=1-\exp (-0.0039733 \times \mathrm{dNBR})
$$

This model had an $R^{2}$ of 0.71 and a standard error of 0.21 . Correlogram analysis of the model residuals did not detect any residual spatial structure. The $t$-test for the value of the coefficient $(t=4.2365, p<0.0001)$, and $F$-test for model goodness of fit $(F=131.8427, p<0.0001)$ were both highly significant. The model was applied to the dNBR image to generate the map of predicted CBI (Fig. 1).

Predicted CBI increased with elevation up to the $725-865 \mathrm{~m}$ class, then decreased slightly at the highest elevations (Fig. 3a), decreased with topographic wetness index (Fig. 3b), and increased with slope (Fig. 3c). Predicted CBI was highest on southwest and west aspects, and lowest on northeast and east aspects (Fig. 3d). Predicted CBI was also higher in pine and outcrop communities than in oak or hemlock communities (Fig. 4). Predicted CBI was highly variable within all of the topographic and vegetation classes.
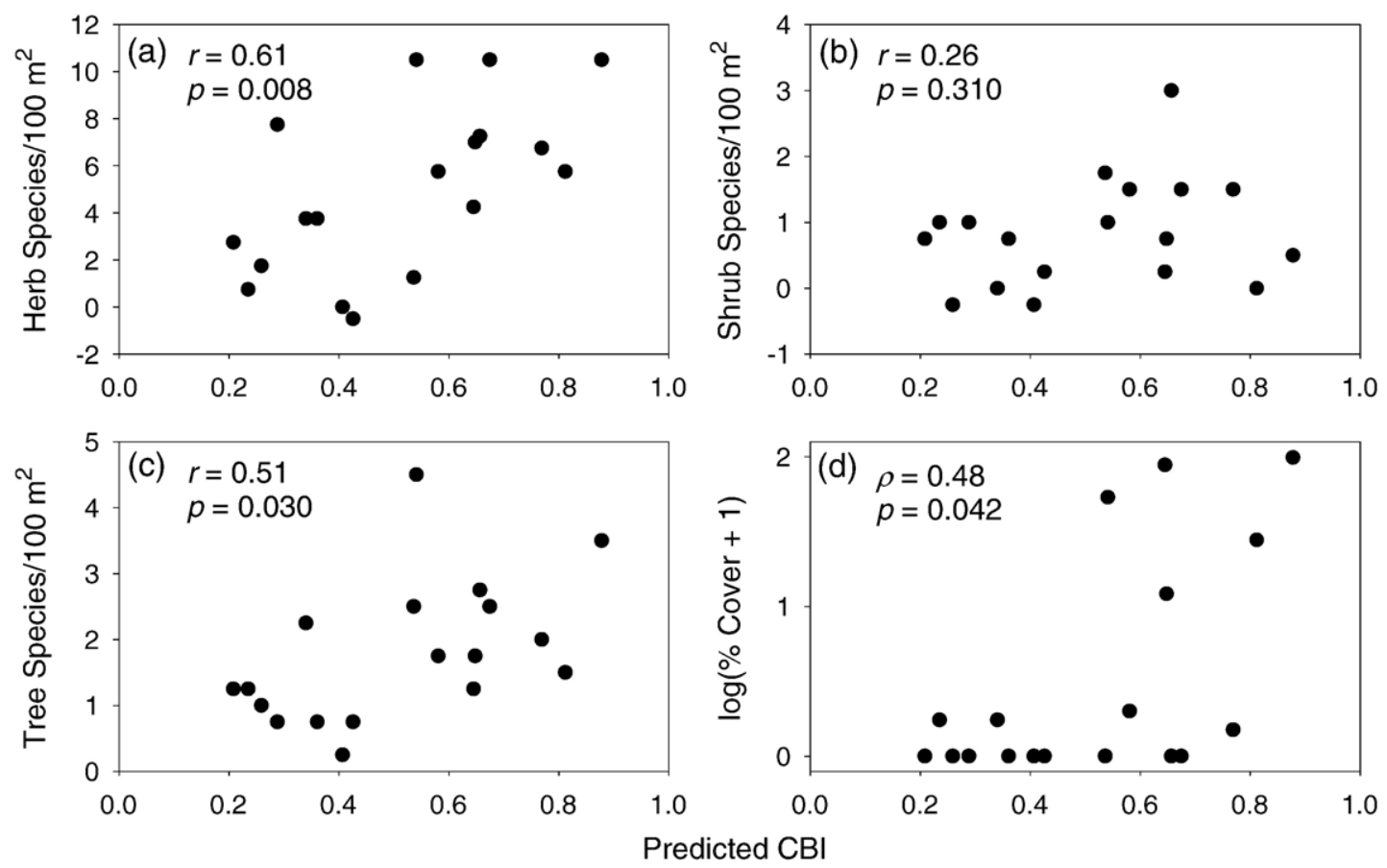

Fig. 6. Scatterplots of composite burn index (predicted as a function of dNBR) versus field measurements of (a) change in herb species richness, (b) change in shrub species richness, (c) change in tree species richness, and (d) post fire cover of eastern yellow pine seedlings $(P$. virginiana, $P$. rigida, $P$. and pungens). $r=$ Pearson correlation coefficient, $\rho=$ Spearman rank correlation coefficient. 
The ordinary least squares regression model had an $R^{2}$ of 0.41 , suggesting that topographic and vegetation constraints had a relatively strong influence on the spatial pattern of fire severity. Predicted CBI increased with elevation, slope, and heat load index, decreased with topographic wetness index, and was higher in pine and hemlock communities than in oak communities (Table 1). The parameter for rocky outcrop communities was not statistically significant, and was dropped from the final model. The standardized topographic coefficients can be interpreted as the change in the arcsine-square root transformed CBI index that would result from an increase of one standard deviation of the predictor variable. The community coefficients can similarly be interpreted as the change that would result from a shift from 0 to $100 \%$ dominance of the community type. The standardized coefficients indicated that elevation had the strongest influence on fire severity out of the topographic variables, whereas aspect and topographic wetness had the weakest influences and slope was intermediate. Pine communities had a stronger influence on fire severity than hemlock communities. The Moran's I correlogram of the residuals indicated that there was considerable spatial autocorrelation in the pattern of fire severity that was not accounted for by the topographic and vegetation variables (Fig. 5).

The autoregressive spatial error model had a pseudo- $R^{2}$ (Nagelkerke, 1991) of 0.77. The Moran's I correlogram of the residuals indicated that the predictor variables, in combination with the spatial error term, accounted for the majority of the spatial pattern of fire severity (Fig. 5). Including the spatial error term modified the coefficients for some of the predictor variables. The effect of elevation was greater in the spatial autoregressive model, and the effects of aspect and topographic wetness were similar to the ordinary least squares model. The effect of slope was considerably less in the spatial autoregressive model than in the ordinary least squares model. The influences of both pine and hemlock communities were lower in the spatial autoregressive model, but pine communities still had had a stronger effect on fire severity than hemlock communities.

Changes in plant species richness were positively correlated with CBI values predicted using satellite imagery (Fig. 6). Statistically significant correlations were found for herbs and trees, but not for shrubs. The cover of post-fire yellow pine seedlings was also positively correlated with CBI. Although only a few plots had pine seedlings cover greater than $10 \%$, these all occurred on sites with a predicted CBI greater than 0.5 (Fig. 6d). In contrast, pine seedlings cover was less than $1 \%$ on all plots with a predicted CBI less than 0.5 .

\section{Discussion}

Multi-temporal analysis of fire severity using dNBR appears to be an effective technique for mapping the severity of large wildfires in the southern Appalachians. The $R^{2}$ of 0.71 for our non-linear regression of CBI versus $\mathrm{dNBR}$ was comparable to values reported in other studies that predict fire severity as a continuous function of remotely sensed variables from Landsat imagery. Maximum $R^{2}$ values for linear relationships between field-based CBI indices and remotely-sensed indices ranged from 0.59 to 0.83 for four fires in interior Alaska (Epting et al., 2005). Post-fire canopy cover following the Warner Creek fire in western Oregon was modeled using a multiple regression equation consisting of pre- and post-burn indices with an $\mathrm{R}^{2}$ of 0.82 . An $R^{2}$ of 0.89 was reported for a polynomial regression of CBI versus dNBR from a burn mapping study in Yosemite National Park (Van Wagtendonk et al., 2004).

Several factors limited our ability to predict fire severity in Linville Gorge with greater accuracy. Our field assessment was carried out several years after the fire, whereas our post-fire satellite image was obtained in the first growing season after the fire. An analysis of field-based severity measurements collected at the same time as the post-fire satellite image would be expected to result in higher accuracy of fire severity predictions. The fact that a reasonably strong relationship was found in spite of this temporal lag suggests that imagery obtained the year after a fire is valuable as an indicator of longer-term changes in addition to immediate fire effects. Many portions of the Linville Gorge fire exhibited local heterogeneity in burn severity, making it difficult to locate large patches with homogeneous dNBR values. This was particularly true for the intermediate levels of fire severity, which often occurred as narrow transition zones between areas of minimal fire effects and complete overstory mortality. Therefore, georegistration errors, global positioning system (GPS) errors, and the limitations of Landsat $\mathrm{TM}$ and ETM + spatial resolution may have greater effects in the heterogeneous forest communities and variable terrain of the Southern Appalachians than in other ecosystems with less spatial variability in vegetation and topography. Finally, although dNBR exhibits strong correlations with field-based metrics of fire severity in a variety of ecosystems, it is not necessarily the best index of fire severity in all situations (Epting et al., 2005; Rogan \& Yool, 2001; Roy et al., 2006).

Topography and vegetation both had strong effects on the spatial pattern of fire severity resulting from the 2000 Linville Gorge Fire. The topographic effects suggested that fire behavior and effects were influenced by spatial variability in site moisture. Elevation had the strongest effect out of the topographic variables, indicating a tendency for higher fire severities on the dry bluffs and upper hillslopes near the top of the gorge. The influences of heat load index and topographic wetness index similarly indicated that fire severity was greatest on sites that received high levels of solar radiation and had relatively dry soils. Rapid upslope fire spread may have contributed to higher fire severities on steep slopes. However, the decreased slope effects in the spatial autoregression model indicated that the influences of slope on fire severity could not be separated from the potentially confounding effects of spatial autocorrelation. High severity in pine-dominated communities reflected greater flammability of conifer fuels, combined with tree mortality and increased fuel loads resulting from a southern pine beetle outbreak in the late 1990's.

The low fire severities in hemlock communities found in the univariate overlay analysis (Fig. 4) reflected the association of T. canadensis with moist areas along ravines and at the bottom of the gorge. However, T. canadensis has thin bark, shallow roots, and flammable foliage, and heavy litter deposits, and is 
considered to be among the most fire-sensitive of all eastern tree species (Godman \& Lancaster, 1990). The positive coefficients for hemlock communities in the multiple regression models indicated that when the influences of topography were controlled for, fire severity in hemlock communities was actually higher than in oak communities because even a low-intensity fire can cause high levels of $T$. canadensis mortality. Similarly, once the effects of higher severity in the mid-elevation pine forests were controlled for in the multivariate regression, the relationship between elevation and fire severity changed from weakly unimodal to strongly linear. These results emphasize the importance of using multiple regression models to disentangle the influences of topography and vegetation on fire severity.

These findings contrast with some boreal and subalpine forests in the western United States and Canada, in which local effects of terrain and fuels are relatively weak for the largest fires burning under the most extreme climate conditions (Bessie \& Johnson, 1995; Fryer \& Johnson, 1988; Turner et al., 1999). The interspersion of pine- and oak-dominated forest communities in Linville Gorge likely had a greater influence on fire behavior than in western landscapes where tree species diversity is lower and conifer forests are the dominant community type. Fire frequency was similarly linked to spatial variability in forest cover types in a boreal mixedwood forest comprised of spruce-, pine-, and deciduous-dominated communities (Cumming, 2001). Fire severity also varied among spruce-, pine-, and aspen dominated communities in a subalpine forests in northwestern Colorado (Bigler et al., 2005). Differential susceptibility of communities to other types of disturbances may reinforce their distinctive responses to fire. In the case of the Linville Gorge fire, the differences in fire severity between pine and oak-dominated communities were likely increased by a southern pine beetle outbreak that altered forest structure and fuels in the pine communities. A positive relationship between pre-fire pine beetle infestation and fire severity was also found for the Yellowstone fires of 1988 (Turner et al., 1999).

Spatial heterogeneity in fire severity translated into variable community responses in Linville Gorge. High severity fires that kill dominant vegetation make resources available and provide opportunities for colonization by new species. A previous study documented strong relationships between field-based metrics of fire severity and post-fire changes in plant community diversity (Reilly et al., 2006). In the present study, herbs and trees, both of which exhibited high levels of post-fire seedling establishment, increased in richness and were correlated with remote-sensing based metrics of fire severity. Shrubs regenerated primarily by sprouting and exhibited comparatively low increases in species richness and weak relationships with fire severity. A detailed analysis of the ecological mechanisms underlying plant community responses to the Linville Gorge fire is provided by Reilly et al. (2006). The present study confirmed that remote sensing-derived metrics of fire severity can serve as predictors of plant community responses to fire.

Burn maps derived from satellite imagery can also be used to identify areas with a high potential for post-fire establishment of eastern yellow pine (P. virginiana, P. rigida, and P. pungens). All three of these species are shade intolerant, and P. rigida and
P. pungens both have serotinous cones. Loss of pine communities dominated by these species is presently a conservation concern, and is exacerbated by fire management policies that limit the occurrence of stand-replacing fires. Several of the field sites in this study had high percent cover of these pine species 3 years after the fire, indicating successful pine seedling establishment in areas that were previously covered with older, decadent pine stands transitioning towards oak dominance (Newell \& Peet, 1998). All of these sites with had a predicted CBI greater than 0.5 , and were in areas that had relatively high pine basal area prior to the fire. Although low levels of regeneration have been observed after some prescribed burns (Elliott et al., 1999), other evidence suggests that prescribed burns can be successful at regenerating pine (Turrill, 1998; Waldrop \& Brose, 1999; Welch \& Waldrop, 2001). Burn severity maps derived from satellite imagery may prove useful for modeling the potential distribution of pine regeneration following prescribed burns and wildfires.

\section{Conclusion}

Landscape-level patterns of fire severity in the southern Appalachians can be mapped based on changes in dNBR derived from multitemporal satellite imagery. Furthermore, these remotely-sensed indices of fire severity have potential for predicting changes in forest community composition and regeneration of fire-dependent tree species. Even though the Linville Gorge fire is considered exceptionally large and severe for these eastern forests, there were still relatively strong influences of topography and pre-fire vegetation on the spatial pattern of fire severity. Fire severity was highest on drier landforms located on upper hillslopes, ridges, and on southwest aspects, and was higher in pine communities impacted by a southern pine beetle outbreak than in other community types. Spatial variability in fire severity in turn influenced the spatial distribution of plant species colonization and forest community change. Thus, large fires in the southern Appalachians appear to reinforce preexisting patterns of landscape heterogeneity and community diversity.

\section{Acknowledgements}

Robert Peet provided access to archived material in the North Carolina Vegetation Survey database. Rachel Spigler, Mark Garner, and Darroc Goolsby provided assistance in the field. Mark Cochrane and three anonymous reviewers provided helpful comments on an earlier version of this manuscript. Funding for this research was provided by the University of Georgia Warnell School of Forest Resources, and the Sigma Xi Grants-in-Aid of Research program.

\section{References}

Anselin, L. (2002). Under the hood: Issues in the specification and interpretation of spatial regression models. Agricultural Economics, 27, 247-267.

Barden, L. S., \& Woods, F. W. (1973). Characteristics of lightning fire in southern Appalachian forests. Proceedings of the Annual Tall Timbers Fire Ecology Conference, 13, (pp. 345-361). 
Bessie, W. C., \& Johnson, E. A. (1995). The relative importance of fuels and weather on fire behavior in sub-alpine forests. Ecology, 76, 747-762.

Beven, K. J., \& Kirkby, M. J. (1979). A physically-based variable contributing area model of basin hydrology. Hydrological Sciences Bulletin, 24, 43-69.

Bigler, C., Kulakowski, D., \& Veblen, T. T. (2005). Multiple disturbance interactions and drought influence fire severity in Rocky Mountain subalpine forests. Ecology, 86, 3018-3029.

Bivand, R. (2002). Spatial econometrics functions in R: Classes and methods. Journal of Geographic Systems, 4, 405-421.

Chavez, P. S. (1996). Image-based atmospheric corrections revisited and improved. Photogrammetric Engineering and Remote Sensing, 62, 1025-1036.

Cocke, A. E., Fule, P. Z., \& Crouse, J. E. (2005). Comparison of burn severity assessments using differenced normalized burn ratio and ground data. International Journal of Wildland Fire, 14, 189-198.

Cumming, S. G. (2001). Forest type and wildfire in the Alberta boreal mixedwood: What do fires burn? Ecological Applications, 11, 97-110.

Delcourt, H. R., \& Delcourt, P. A. (1997). Pre-Columbian Native American use of fire on southern Appalachian landscapes. Conservation Biology, 11, $1010-1014$

Elliott, K. J., Hendrick, R. L., Major, A. E., Vose, J. M., \& Swank, W. T. (1999). Vegetation dynamics after a prescribed fire in the southern Appalachians. Forest Ecology and Management, 114, 199-213.

Epting, J., Verbyla, D., \& Sorbel, B. (2005). Evaluation of remotely sensed indices for assessing burn severity in interior Alaska using Landsat TM and ETM+. Remote Sensing of Environment, 96, 328-339.

Fryer, G. I., \& Johnson, E. A. (1988). Reconstructing fire behaviour and effects in a subapline forest. Journal of Applied Ecology, 25, 1063-1072.

Godman, R. M., \& Lancaster, K. (1990). Eastern Hemlock. In R. M. Burns \& B. H. Honkala (Eds.), Silvics of North AmericaConifers, Vol. 1. (pp. 604-612). Washington DC: USDA Forest Service Agricultural Handbook 654.

Haining, R. (2003). Spatial data analysis: Theory and practice. Cambridge: Cambridge University Press.

Harcombe, P. A., Greene, S. E., Kramer, M. G., Acker, S. A., Spies, T. A., \& Valentine, T. (2004). The influence of fire and windthrow dynamics on a coastal spruce-hemlock forest in Oregon, USA, based on aerial photographs spanning 40 years. Forest Ecology and Management, 194, 71-82.

Harmon, M. E. (1982). Fire history of the westernmost portion of Great Smoky Mountains National Park. Bulletin of the Torrey Botanical Society, 109, $74-79$.

Harrod, J. C., White, P. S., \& Harmon, M. E. (1998). Changes in xeric forests of western Great Smoky Mountains National Park, 1936-1995. Castanea, 63, $346-360$.

Key, C. H., \& Benson, N. C. (2002). Fire effects monitoring and inventory protocol - Landscape assessment. Missoula, MT: USDA Forest Service Fire Science Laboratory.

Kushla, J. D., \& Ripple, W. J. (1998). Assessing wildfire effects with Landsat Thematic Mapper data. International Journal of Remote Sensing, 19, 2493-2507.

McCune, B., \& Keon, D. (2002). Equations for potential annual direct incident radiation and heat load. Journal of Vegetation Science, 13, 603-606.

Miller, J. D., \& Yool, S. R. (2002). Mapping forest post-fire canopy consumption in several overstory types using multi-temporal Landsat TM and ETM data. Remote Sensing of Environment, 82, 481-496.

Moran, S. M., Slater, P. N., \& Teillet, P. M. (1992). Evaluation of simplified procedures for retrieval of land surface reflectance factors from satellite sensor output. Remote Sensing of Environment, 41, 169-184.
Nagelkerke, N. J. D. (1991). A note on a general definition of the coefficient of determination. Biometrika, 78, 691-692.

Newell, C. L., \& Peet, R. K. (1998). Vegetation of Linville Gorge Wilderness, North Carolina. Castanea, 63, 275-322.

Nunes, M. C. S., Vasconcelos, M. J., Pereira, J. M. C., Dasgupta, N., \& Alldredge, R. J. (2005). Land cover type and fire in Portugal: Do fires burn land cover selectively? Landscape Ecology, 20, 661-673.

R Development Core Team. (2005). R: A language and environment for statistical computing. Vienna, Austria: R Foundation for Statistical Computing, ISBN 3-900051-07-0.

Reilly, M. J. (2004). Plant community dynamics following wildfire in the southern Appalachians: Changes in diversity at multiple spatial scales. M.S. thesis, University of Georgia.

Reilly, M. J., Wimberly, M. C., \& Newell, C. L. (2006). Wildfire effects on plant species richness at multiple spatial scales in communities of the southern Appalachians. Journal of Ecology, 94, 118-130.

Rogan, J., \& Yool, S. R. (2001). Mapping fire-induced vegetation depletion in the Peloncillo Mountains, Arizona and New Mexico. International Journal of Remote Sensing, 22, 3101-3121.

Romme, W. H., Everham, E. H., Frelich, L. E., Moritz, M. A., \& Sparks, R. E. (1998). Are large, infrequent disturbances qualitatively different from small, frequent disturbances? Ecosystems, 1, 524-534.

Roy, D. P., Boschetti, L., \& Trigg, S. N. (2006). Remote sensing of fire severity: Assessing the performance of the normalized burn ratio. IEEE Geoscience and Remote Sensing Letters, 3, 112-116.

Schmidt, F., \& Persson, A. (2003). Comparison of DEM data capture and topographic wetness indices. Precision Agriculture, 4, 179-192.

Turner, M. G., Hargrove, W. W., Gardner, R. H., \& Romme, W. H. (1994). Effects of fire on landscape heterogeneity in Yellowstone National Park. Journal of Vegetation Science, 5, 731-742.

Turner, M. G., \& Romme, W. H. (1994). Landscape dynamics in crown fire ecosystems. Landscape Ecology, 9, 59-77.

Turner, M. G., Romme, W. H., \& Gardner, R. H. (1999). Prefire heterogeneity, fire severity, and early postfire plant reestablishment in subalpine forests of Yellowstone National Park, Wyoming. International Journal of Wildland Fire, 9, 21-36.

Turrill, N. L. (1998). Using prescribed fire to regenerate Pinus echinata, P. pungens, and P. rigida in the southern Appalachian mountains. Ph.D. Dissertation, University of Tennessee.

Van Wagtendonk, J. W., Root, R. R., \& Key, C. H. (2004). Comparison of AVIRIS and Landsat ETM+ detection capabilities for burn severity. Remote Sensing of Environment, 92, 397-408.

Waldrop, T. A., \& Brose, P. H. (1999). A comparison of fire intensity levels for stand replacement of table mountain pine (Pinus pungens, Lamb.). Forest Ecology and Management, 113, 155-166.

Welch, N. T., \& Waldrop, T. A. (2001). Restoring table mountain pine (Pinus pungens Lamb.) communities with prescribed fire: An overview of current research. Castanea, 66.

Williams, C. E., \& Johnson, W. C. (1992). Factors affecting the recruitment of Pinus pungens in the southern Appalachian mountains. Canadian Journal of Forest Research, 22, 878-887.

Wimberly, M. C., \& Spies, T. A. (2001). Influences of environment and disturbance on forest patterns in coastal Oregon watersheds. Ecology, 82, $1443-1459$. 